\title{
DINÂMICA SAZONAL DE PROCESSOS COSTEIROS E ESTUARINOS EM SISTEMA DE PRAIAS ARENOSAS E ILHAS BARREIRA NO NORDESTE DO BRASIL
}

\author{
SEASONAL DYNAMICS OF COASTAL AND ESTUARINE \\ PROCESSES IN SANDY BEACHES AND BARRIER ISLANDS \\ SYSTEM IN NORTHEAST BRAZIL
}

\author{
Marcelo Soares Teles Santos \\ Universidade Federal do Recôncavo da Bahia - UFRB - Centro de Ciências Exatas e Tecnológicas - CETEC \\ Câmpus Universitário - CEP 44380-000 - Cruz das Almas/BA \\ E-mail:mstsantos@ufrb.edu.br
}

Venerando Eustáquio Amaro

Universidade Federal do Rio Grande do Norte - UFRN - Departamento de Geologia - DGEO Campus Universitário - CEP 59078-970 - Natal/RN

E-mail:amaro@geologia.ufrn.br

\section{Informações sobre o Artigo \\ Data de Recebimento: \\ $19 / 05 / 2012$ \\ Data de Aprovação: \\ 07/08/2013 \\ Palavras-chave: \\ Linha de Costa, Modelo Digital de Elevação (MDE); monitoramento costeiro.}

\section{Keywords:}

Coastline; Digital Elevation Model (DEM); coastal monitoring.

\begin{abstract}
Resumo
Este trabalho monitorou a dinâmica intra-anual (sazonal) de um sistema de praias arenosas, ilhas barreiras e canais de maré localizados no Litoral Setentrional do Estado do Rio Grande do Norte, Nordeste do Brasil, área de alta sensibilidade ambiental e sob a influência de atividades industriais como a petrolífera. A estratégia metodológica consistiu em geração e comparação de Linhas de Costa (LC) e Modelos Digitais de Elevação (MDE) das praias e ilhas barreiras monitoradas, na escala trimestral, e nas correlações entre as variações superficiais e volumétricas medidas e a atuação dos agentes dinâmicos costeiros modeladores do relevo (ventos, ondas, correntes e marés) durante os intervalos dos monitoramentos. Os resultados permitiram a identificação das causas e consequências da intensa erosão costeira ocorrida nas praias expostas, analisar a recuperação dessas praias arenosas e as acresções ocorridas nos canais de maré e estuarinos, entender a influência da hidrodinâmica na dinâmica sedimentar sazonal e verificar os fluxos dominantes do transporte sedimentar, se o hidrodinâmico na LC ou o eólico nas superfícies das ilhas e praias arenosas. As análises dos resultados das modificações de curto prazo vêm sendo utilizadas como subsídio a projetos de mitigação de impactos ambientais que visam o convívio das atividades industriais de risco e os ecossistemas costeiros.
\end{abstract}

\section{Abstract}

This study has monitored intra-annual (seasonal) dynamics of a sandy beach, barrier islands, and tidal channels system located on the northern coast of Rio Grande do Norte, Northeast Brazil, an area of high environmental sensitivity and under the influence of 
industrial activities such as petroleum industry. The methodological strategy consisted of generation and comparison of Coastlines (CL) and Digital Elevation Models (DEM) of quarterly monitored beaches and barrier islands, correlations between measured superficial and volumetric variations as well as the performance of dynamic coastal agents that are relief modelers (winds, waves, and currents) during the monitoring interval. The results allowed the identification of the causes and consequences of intensive coastal erosion occurring on exposed beaches, analyzing the recovery of exposed beaches and accretions occurring in tidal channels and estuaries, to understand the influence of hydrodynamics on seasonal sediment dynamics, and check the dominant sediment transport flows, hydrodynamic in CL or wind on island and sandy beach surfaces. Analyzes of results of short term changes has been used as subsidy for projects to mitigate the environmental impacts, which aim at the coexistence of industrial activities and coastal ecosystems.

\section{Introdução}

A área de estudo, localizada no Litoral Setentrional do Estado do Rio Grande do Norte (RN), entre os municípios de Macau e Guamaré (Figura 1), é constituída por um sistema de praias oceânicas arenosas (praias de Soledade e Minhoto), ilhas barreiras (ilhas da Ponta do Tubarão e do Fernandez) e canais de maré submetidos à intensa ação de processos costeiros que promovem as variações nas Linhas de Costa (doravante apenas LC), o transporte eólico e litorâneo, a erosão generalizada, as alterações no balanço de sedimentos, as aberturas e fechamentos de canais de marés e a formação de novas ilhas barreiras e barras arenosas (Grigio et al., 2005; Chaves et al., 2006; Souto, 2009; Nascimento, 2009; Santos \& Amaro, 2011a). A intensa dinâmica costeira (erosão/acresção sedimentar) modifica a morfologia costeira mesmo em curtos intervalos de tempo, em conformidade com as mudanças sazonais intra-anuais, e interferem nas atividades industriais localizadas no litoral, tais como a salineira, a petrolífera, a eólica e a de carcinicultura, a maioria instalada no prisma praial emerso, constituindo alto risco ambiental.

O objetivo deste trabalho foi o monitoramento da dinâmica intranual (sazonal) da área de estudo para analisar as causas e conseqüências dos intensos processos atuantes em períodos de curto prazo para, futuramente, servir de base qualitativa e quantitativa do balanço sedimentar e das alterações da morfologia costeira em projetos de mitigação de impactos ambientais. A estratégia metodológica consistiu na geração e comparação de LC e Modelos Digitais de Elevação (MDE) das praias e ilhas monitoradas, em épocas cujos parâmetros dos agentes dinâmicos costeiros modeladores do relevo (ventos, ondas e correntes) fossem reconhecidos, e nas correlações entre as variações superficiais e volumétricas medidas e a atuação dos agentes durante os intervalos dos monitoramentos. A comparação entre as LC e os MDE permitiu a identificação e a mensuração da variação da LC e das áreas e volumes de erosão/acresção, cálculo do volume e da orientação do transporte de sedimentos na LC e nas superfícies de praias, além da análise do balanço e do suprimento sedimentares.

Alguns trabalhos sobre monitoramento costeiro foram desenvolvidos em várias partes do mundo a partir da comparação multitemporal de LC obtidas por diversas técnicas de aquisição e modelagem (Klemas, 2011; Cowart et al., 2010; Rocha et al., 2009; Baptista et al., 2008; Esteves et al., 2006; Moore et al., 2006; Boak \& Turner, 2005). Nesses trabalhos observa-se a multiplicidade de indicadores de LC, definidos principalmente em função da técnica de aquisição de dados, da escala espaço-temporal de observação e de suas aplicações, o que inviabiliza a comparação espaço-temporal entre os produtos gerados. Nos estudos de dinâmica sazonal da área de estudo, onde as variações ocorrem em intervalos relativamente curtos (intranual) e ainda interferem diretamente nas atividades antrópicas instaladas nas proximidades da LC, a definição mais adequada para LC consistiu, genericamente, na linha dinâmica que marca a interface física entre terra e água. Por esse motivo, a LC está condicionada aos processos dinâmicos atuantes nesse ambiente (marés, ondas, correntes, ventos, nível do lençol freático, entre outros). Assim, as variações mensuradas podem ser utilizadas de maneira adequada nas atividades envolvendo as questões relativas ao planejamento de uso e ocupação dos setores litorâneos, que nessa região do RN estão sob a forte pressão antrópica das atividades industriais em conflito com a necessária proteção ambiental dos ecossistemas costeiros.

A metodologia geodésica baseada no uso do Global Positioning System (GPS) na aquisição de dados in situ permitiu a determinação de LC e MDE, relacionadas em uma maré específica em preamar, produtos esses georreferenciados e relacionados ao nível médio dos mares com alta acurácia em relação ao Sistema Geodésico Brasileiro (SGB). Essa estratégia permitiu a comparação espaço-temporal dos modelos, o que possibilitou a análise das modificações na morfodinâmica praial na escala de detalhe. As características da metodologia empregada permitiram apresentação de contribuições importantes ao monitoramento de litorais arenosos, especialmente com o conhecimento dos mecanismos envolvidos na dinâmica sedimentar de curta duração de sistemas tropicais de praias oceânicas, ilhas barreiras e canais de maré, tanto nas componentes planimétrica (variações das LC) e planialtimétrica (variações nas superfícies costeiras) com alta precisão. Além disso, a precisão obtida nas observações e modelagens permitiu que as variações fossem compartimentadas em segmentos, em função das diferentes condições hidrodinâmicas e eólicas atuantes na dinâmica sedimentar da área de estudo. 


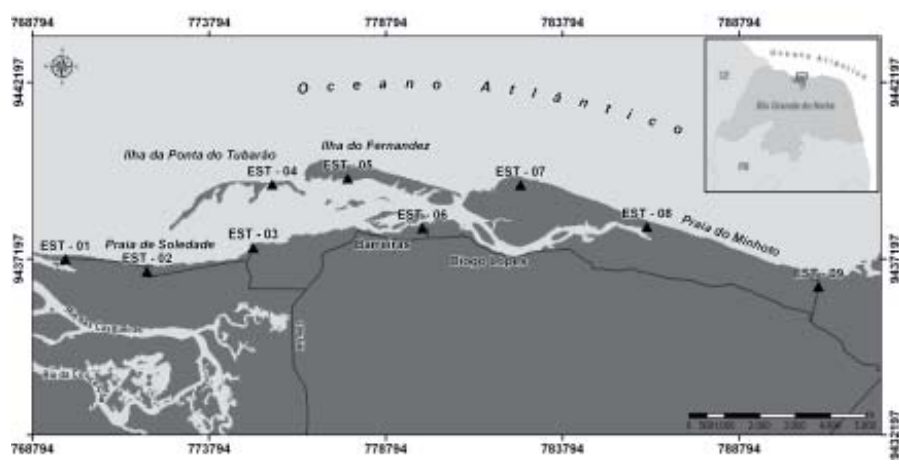

Figura 1 - Mapa da área de estudo com a localização geográfica das nove estações da Rede Geodésica do Litoral Setentrional do RN (EST-01 a EST-09) e dos quatro trechos utilizados nos monitoramentos costeiros (Praia de Soledade entre as estações EST-01 e EST-03, Ilha da Ponta do Tubarão, Ilha do Fernandez, e Praia do Minhoto entre as estações EST-07 e EST-09). Modificado de Santos \& Amaro (2011a).

\section{Caracterização da área de estudo}

Os dados climáticos foram medidos entre os anos de 1961 e 1990 na Estação Maregráfica de Macau (Instituto Nacional de Meteorologia, INMET). O clima foi classificado como quente e semiárido e apresenta duas estações pluviométricas distintas e bem definidas: a estação úmida com quatro meses (de fevereiro a maio) e a estação seca com oito meses (de junho a janeiro). A precipitação apresentou média mensal de $50 \mathrm{~mm}$ ao longo do ano, com média mensal de $118,4 \mathrm{~mm}$ na estação úmida e de $15,8 \mathrm{~mm}$ na estação seca. A insolação é uma das mais elevadas do Brasil, com média diária de 7,22 h, mínima de 6,0 h em fevereiro (estação úmida) e máxima de 8,3 h em outubro (estação seca). A grande incidência de energia solar ocorre com temperaturas elevadas e pequenas variações ao longo do ano, com média anual de $26,9^{\circ} \mathrm{C}$, mínimo de $27,0^{\circ} \mathrm{C}$ em maio (estação úmida) e máximo de $27,5^{\circ} \mathrm{C}$ em janeiro (estação seca). Em termos absolutos, a temperatura pode chegar a ultrapassar os $40^{\circ} \mathrm{C}$ no mês de novembro. Devido ás características climáticas, os principais rios da região são intermitentes, ou seja, possuem fluxo apenas durante o período das chuvas (março a maio); a partir de junho, com o início do período seco, o fluxo desses rios diminui continuamente, chegando a ser nulo em novembro, mês de maior temperatura anual, e permanece assim até fevereiro, no final do período seco (Nascimento, 2009; Souto, 2009).

Os ventos da área de estudo, segundo Caldas (2002 apud Souto, 2009) são marcados por duas direções principais: um SE e outro ENE. Os ventos de SE surgem geralmente entre os meses de março e julho, apresentando-se mais suaves, com velocidades médias mensais de $4,8 \mathrm{~m} / \mathrm{s}$. Por outro lado, os ventos de ENE, que surgem entre os meses de agosto e dezembro, apresentam velocidades mais fortes, com médias mensais de 7,7m/s (Santos, 2003 apud Souto, 2009). As ondas, segundo Souto (2009), ao se aproximarem da zona costeira apresentam um fluxo com a mesma direção dos ventos dominantes (ENE). De acordo com Chaves et al. (2006), que realizaram um trabalho de monitoramento com medidas dos parâmetros do meio físico, a altura significativa das ondas variou entre 0,125 a $0,722 \mathrm{~m}$, onde as alturas máximas e mínimas ocorreram nos meses de novembro e maio, respectivamente. A corrente de deriva litorânea, segundo Souto (2009), tem direção preferencial W gerada pela correlação entre a orientação E-W da LC, a direção preferencial dos ventos (NE-E) e ao fluxo de ondas provenientes de NE-E. As correntes superficiais na região de Macau apresentam velocidades máximas de $1,103 \mathrm{~m} / \mathrm{s}$ e mínimas de $0,171 \mathrm{~m} / \mathrm{s}$ para $\mathrm{W}$, nos meses de novembro e maio, respectivamente (Chaves et al., 2006). As marés litorâneas possuem regime de mesomaré, que é caracterizada pelas marés do tipo semidiurnas em relação ao período de oscilação em torno de 12 $\mathrm{h}$, apresentando por dia duas marés de preamar e duas marés de baixamar, com alturas de marés de 2 a 4 metros.

\section{Metodologia}

As datas dos levantamentos foram definidas em função do padrão de dinâmica sedimentar presente na área de estudo, que determinou os ciclos de construção (acresção) e destruição (erosão) dessas praias arenosas (Wright \& Short, 1984). Na área de estudo, entre os meses de março e julho predominam os ventos suaves de SE e ondas de baixa energia, ou seja, o período construtivo, e entre os meses de agosto e fevereiro predominam os ventos fortes de NE e ondas de alta energia, ou seja, o período destrutivo (Figura 2). Assim, para monitorar o ciclo anual, os levantamentos foram realizados trimestralmente em datas correspondentes ao início, meio e fim dos períodos construtivos e destrutivos das praias expostas, com aproximadamente 3 meses de diferença entre eles e nas 4 estações do ano: maio de 2010 (outono), agosto de 2010 (inverno), novembro de 2010 (primavera), e fevereiro de 2011 (verão). Para encerramento da avaliação do ciclo anual foi realizado um levantamento em maio de 2011 (outono). Eventos extremos, tais como situações de marés meteorológicas adversas, provocam erosão sem que isso venha a representar necessariamente uma tendência, pois nessas situações a praia tende a retornar à sua configuração espontaneamente após a volta às condições de bom tempo, por não significar alterações no padrão de distribuição sedimentar (Guerra \& Jorge, 2013). Assim, como o monitoramento realizado no presente trabalho é contínuo, conta-se que nas comparações trimestrais ao longo do tempo os eventos ocorridos fora do padrão esperado para os intervalos sazonais tenham seus efeitos computados, intrinsecamente. 


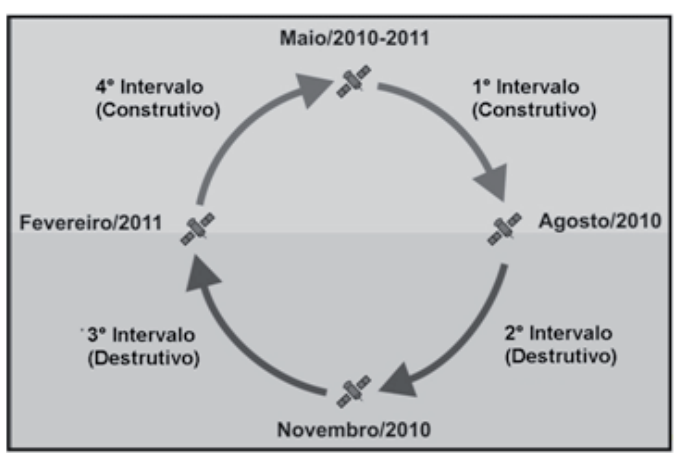

Figura 2 - Intervalos de monitoramento e padrão de dinâmica sedimentar da área de estudo, de acordo com informações obtidas em Souto (2009) e Nascimento (2009). Os intervalos construtivos são característicos de ventos (SE) e ondas (NE) de baixa energia e os destrutivos de ventos (ENE) e ondas (NE) de alta energia.

As coordenadas geodésicas (latitude, longitude e altitude geométrica) e as altitudes ortométrica dos pontos amostrais definidores das LC e dos MDE da área de estudo foram determinadas pelo posicionamento e altimetria por Global Navigation Satellite Systems (GNSS). As coordenadas foram determinadas com o posicionamento GNSS pelo método relativo cinemático (Monico, 2007; Seeber, 1993) a partir de estações da Rede GNSS do Litoral Setentrional do Estado do Rio Grande do Norte (RGLS), implantadas na área de estudo para fornecer linhas de base curtas (menores do que 3,5 km) ao posicionamento GNSS em toda a área de estudo e que possuem coordenadas geodésicas e altitudes ortométricas de precisão (Santos \& Amaro, 2011a). Os receptores utilizados em campo foram do modelo Trimble R3 que possuem precisão nominal horizontal de $5 \mathrm{~mm}+1$ ppm e vertical de $5 \mathrm{~mm}+2 \mathrm{ppm}$ com as observações da fase da onda portadora na frequência L1. O receptor móvel foi acoplado a um quadriciclo motorizado e programado para coletar dados no modo cinemático em função do tempo e com intervalo de gravação de dados de $1 \mathrm{~s}$, o qual proporciona uma densidade de 3.600 pontos/hora. As altitudes foram determinadas com a altimetria GNSS pelo método relativo (Santos \& Sá, 2006; Featherstone et al., 1998) a partir de estações de referência da RGLS e do modelo geoidal do Instituto Brasileiro de Geografia e Estatística (IBGE), modelo MAPGEO2004 (Santos; Amaro; Souto, 2011b; IBGE, 2011).

No levantamento das LC foram coletados pontos topográficos planialtimétricos ao longo dos perfis longitudinais que a definem. Neste trabalho, a LC foi definida como o alcance máximo da linha d'água na maré de quadratura em preamar, ou seja, o limite do espraiamento das ondas na face de praia, como em Souto (2009). A maré de quadratura foi escolhida em função da logística e da segurança de operação, pois, na maré de sizígia não seria possível acesso para medições em certos trechos da área de estudo. No entanto, o uso da mesma maré em todos os levantamentos garantiu que as LC fossem determinadas sob as mesmas condições, fator essencial ao monitoramento sazonal de precisão. As variações das LC foram calculadas pelo método dos transectos, que consistem em linhas virtuais geradas ao longo da costa em distâncias regulares e perpendicularmente a uma linha base paralela à LC, posicionada virtualmente no continente ou no mar. Para um determinado local o transecto de uma LC consiste na distância entre a LC e a linha base. Assim, a variação entre duas LC é calculada pela subtração dos transectos das duas LC, ou seja, é a distância entre as duas LC ao longo do alinhamento do transecto. As seguintes convenções são utilizadas: valores negativos representam recuo da LC ou erosão e valores positivos representam avanço da LC ou acresção. Análises de mudanças na LC têm sido realizadas com frequência por programas computacionais que realizam os cálculos dos transectos automaticamente. Segundo Cowart et al. (2010), o programa Digital Shoreline Analysis System (DSAS), criado e disponibilizado pela United States Geological Survey (USGS), é o mais utilizado na literatura. No entanto, devido á complexidade e intensidade das variações das LC, além do crescimento das praias e ilhas no sentido Oeste ao longo do tempo, optou-se por realizar os cálculos das variações das LC no modo semiautomático com o programa Topograph versão 3.78, da Chair Pointer Tecnologia.

Nos levantamentos das superfícies de praia, realizados logo após o levantamento das LC, foram coletados pontos topográficos planialtimétricos em perfis representativos das feições morfológicas geralmente encontradas nas áreas costeiras, que incluem toda a praia emersa, como em Baptista et al. (2008). Os MDE foram gerados pela interpolação por triangulação com uso da técnica Triangulated Irregular Network (TIN) e os pontos foram conectados de acordo com a triangulação de Delaunay, a qual usa o critério da maximização dos ângulos mínimos de cada triângulo (Santos; Souto; Amaro, 2011). As variações dos MDE foram calculadas pela subtração entre os modelos com o método da álgebra de mapas, no qual os modelos são convertidos para o formato matricial e a cada pixel da imagem gerada é atribuído um valor de altitude (por interpolação dos dados de origem). A subtração dos modelos é então efetuada pixel-a-pixel, de acordo com a localização espacial. Os cálculos das variações dos MDE por álgebra de mapas foram realizados com o software ArcGIS, versão 9.2, da ESRI.

O controle de qualidade dos MDE foi realizado a partir de um conjunto de pontos de controle selecionados aleatoriamente na área de estudo e que não foram usados na geração dos modelos, como em Santos; Souto; Amaro (2011). Suas coordenadas e altitudes foram determinadas pelo mesmo método de posicionamento usado nos pontos definidores das LC e dos MDE, porém, em várias seções. Nos 30 pontos de controle utilizados em cada modelo, os resíduos obtidos entre as altitudes de referência e as dos modelos apresentaram média e desvio padrão decimétricos. Como as variações trimestrais 
na área de estudo ocorrem tipicamente em valores maiores do que $10 \mathrm{~cm}$, os modelos possuem acurácia suficiente para detectar as variações temporais medidas.

Na metodologia empregada, o uso do GPS como fonte de dados permite obter MDE georreferenciados e com altitudes relacionadas ao SGB, como em Santos et al. (2011b). Por ser um produto digital, a visualização espacial dos elementos do modelo independe da escala, o que permite análises micromorfológicas em áreas de grandes extensões, através de programas computacionais específicos. Por ser um produto georreferenciado, o modelo fornece a localização geográfica das feições geomorfológicas presentes na área, além de suas interrelações espaciais, o que o torna útil na compreensão das variações morfológicas no domínio espacial, auxiliando na compartimentação morfológica e no entendimento das modificações ocorridas diante das ações das forçantes hidrodinâmicas. Por estarem relacionadas ao SGB, as altitudes das feições morfológicas podem ser comparadas com as de outros modelos da área de estudo ou de outras áreas, além de fornecerem boa precisão altimétrica em relação ao nível médio dos mares. O georreferenciamento permite ainda a comparação multitemporal dos modelos digitais, o que possibilita a análise da morfodinâmica praial no domínio temporal, no mesmo nível de detalhe em que as feições morfológicas foram modeladas.

\section{Resultados e discussões}

Este item apresenta os resultados obtidos no monitoramento geodésico da área de estudo. A Seção (4.1) apresenta as variações espaciais e temporais nas LC e nos MDE, enquanto a Seção (4.2) analisa as causas da dinâmica costeira ocorrida ao longo dos intervalos de monitoramento.

\section{Variações superficiais nas LC e volumétricas nos MDE}

As Figuras 3 a 6 apresentam as LC de referência (em maio de 2010) e suas variações temporais (recuo ou avanço da LC), respectivamente, da Praia de Soledade, da Ilha Ponta do Tubarão, da Ilha do Fernandez e da Praia do Minhoto. As variações foram calculadas em função dos transectos, gerados a cada $100 \mathrm{~m}$ ao longo da linha base, de oeste para leste. Para efeito de análises, as LC foram compartimentadas em função da exposição às ondas de mar aberto, sendo consideradas praias expostas, submetidas às ondas, às correntes de deriva litorânea, às correntes de maré e aos ventos; e canais de maré e estuários, submetidos às correntes de maré e aos ventos. As variações médias ocorridas nos diversos segmentos de LC foram apresentadas sob duas escalas: no intervalo anual (resultante) e no intervalo trimestral (primeiro ao quarto). A escala anual representa os recuos ou avanços da LC acumuladas durante o ciclo anual de construção e destruição das praias que são importantes para identificar tendências de variações das LC e a recuperação das praias ao longo do ciclo monitorado. A escala trimestral representa as variações das LC ocorridas ao longo do ciclo monitorado que mostram o padrão de distribuição das variações trimestrais, importantes para o conhecimento dos processos costeiros sazonais ocorridos ao longo do ano e que são responsáveis pela resultante anual.

A Figura 7 ilustra o fluxograma do balanço sedimentar volumétrico para a área de estudo, no qual as variações em volume dos MDE foram apresentadas de acordo com a compartimentação da área em volume total (superfície e LC), volume na superfície da praia ou ilha, e volume na LC.

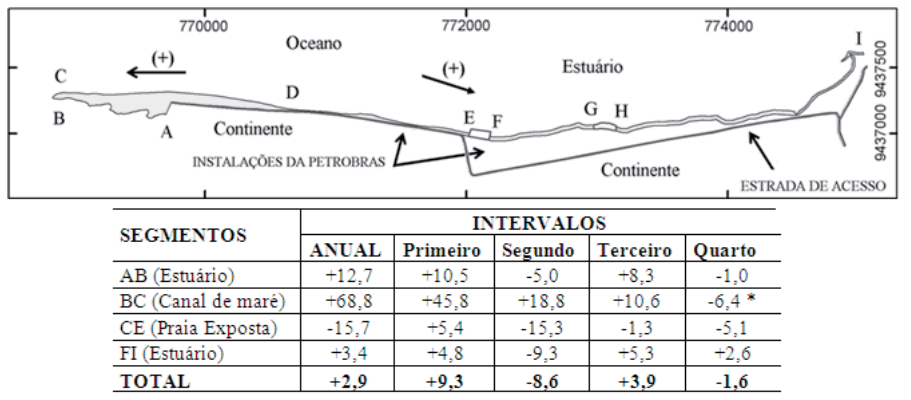

Figura 3 - Variações nas linhas de costa da Praia da Soledade. a) Linhas de costa de referência em maio de 2010. b) Variações das linhas de costa (trimestral e resultante anual). O segmento oeste (ponto A ao E) é exposto ás ondas de mar aberto enquanto o segmento leste (pontos $F$ ao I) é protegido das ondas pela presença das ilhas barreiras que bloqueiam a incidencia das ondas vindas de nordeste. Nos segmentos EF e GH estão os limites oceânicos de instalações de campos petroliferos localizadas sobre a LC e nos quais foram implantadas estruturas de contenção de erosão. As setas com sinal positivo indicam o sentido de erosão, transporte e acresção de sedimentos.

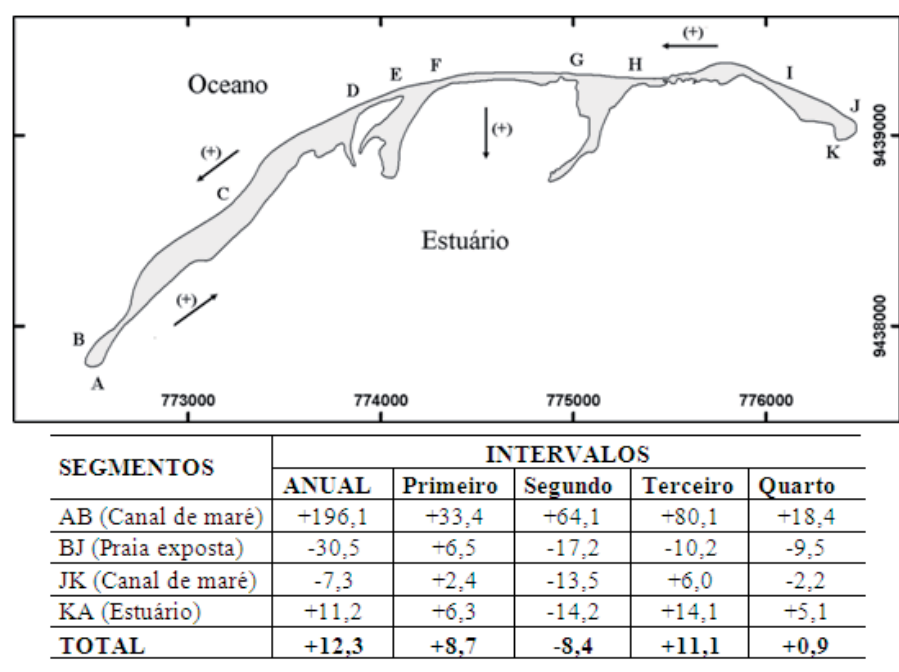

Figura 4 - Variações na linha de costa da Ilha Ponta do Tubarão. a) Linhas de costa de referência em maio de 2010. b) Variações das linhas de costa (trimestral e resultante anual). O segmento norte (pontos $A$ ao $K$ ) é exposto às ondas enquanto e o segmento sul (pontos $K$ ao A) é protegido. As setas com sinal positivo indicam o sentido de erosão, transporte e acresção de sedimentos. 


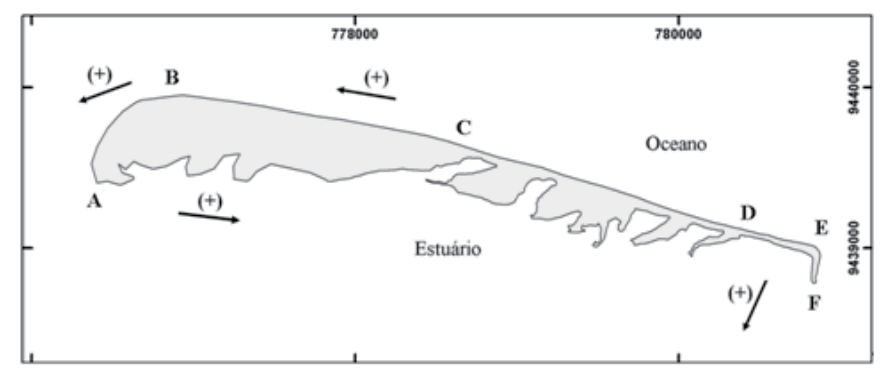

\begin{tabular}{l|c|c|c|c|c}
\hline \multirow{2}{*}{ SEGMENTOS } & \multicolumn{5}{|c}{ INTERVALOS } \\
\cline { 2 - 6 } & ANUAL & Primeiro & Segundo & Terceiro & Quarto \\
\hline AB (Canal de maré) & $+155,4$ & $+14,2$ & $+65,3$ & $+47,2$ & $+28,6$ \\
\hline BE (Praia exposta) & $-17,9$ & $+0,2$ & $-7,1$ & $-4,8$ & $-6,2$ \\
\hline EF (Canal de maré) & $-137,7$ & $+9,0$ & $+4,4$ & $+0,4$ & $-137,7 * *$ \\
\hline FA (Estuário) & $+18,6$ & $+12,8$ & $-5,2$ & $+8,2$ & $+2,8$ \\
\hline TOTAL & $+\mathbf{2 , 0}$ & $+\mathbf{7 , 4}$ & $\mathbf{- 0 , 9}$ & $+\mathbf{4 , 9}$ & $\mathbf{- 8 , 5}$ \\
\hline
\end{tabular}

Figura 5 - Variações na linha de costa da Ilha do Fernandez. a) Linhas de costa de referência em maio de 2010. b) Variações das linhas de costa (trimestral e resultante anual). O segmento norte (pontos $A$ ao $F$ ) é exposto às ondas e o segmento sul (pontos $F$ ao A) é protegido. As setas com sinal positivo indicam o sentido de erosão, transporte e acresção de sedimentos.

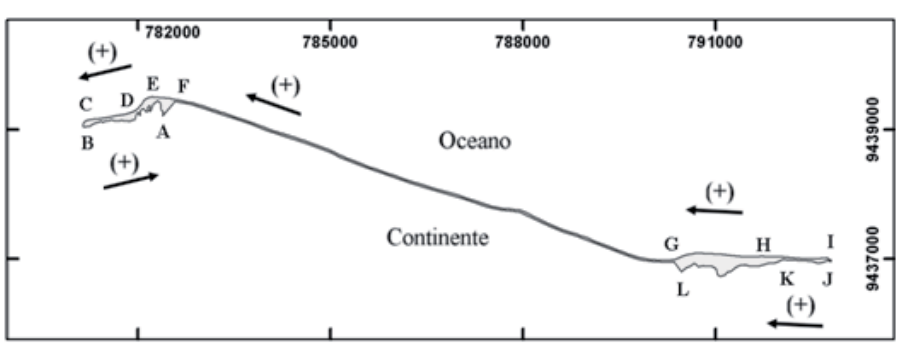

\begin{tabular}{l|c|c|c|c|c}
\hline \multirow{2}{*}{ SEGMENTOS } & \multicolumn{5}{|c}{ INTERVALOS } \\
\cline { 2 - 6 } & ANUAL & Primeiro & Segundo & Terceiro & Quarto \\
\hline AB (Estuário) & $+0,7$ & $+0,6$ & $-0,2$ & $+2,1$ & $-1,8$ \\
\hline BC (Canal de maré) & $+204,4$ & $+52,7$ & $+62,6$ & $+44,3$ & $+44,6$ \\
\hline CF (Praia exposta) & $+3,5$ & $+12,4$ & $-5,0$ & $-0,4$ & $-3,5$ \\
\hline FG (Praia exposta) & $+1,2$ & $+4,2$ & $-7,5$ & $+3,9$ & $+0,5$ \\
\hline GI (Praia exposta) & $-49,7$ & $+8,1$ & $-28,3$ & $-20,0$ & $-9,5$ \\
\hline IJ (Canal de maré) & ---- & $+20,8$ & ---- & ---- & $--\cdot-$ \\
\hline JL(Estuário) & $+30,9$ & $+3,5$ & $+0,1$ & $+28,7$ & $-1,5$ \\
\hline TOTAL & $+\mathbf{2 , 6}$ & $+\mathbf{7 , 2}$ & $-\mathbf{1 1 , 6}$ & $+\mathbf{2 , 1}$ & $-\mathbf{1 , 4}$ \\
\hline
\end{tabular}

Figura 6 - Variações na linha de costa da Praia do Minhoto. a) Linhas de costa de referência em maio de 2010. b) Variações das linhas de costa (trimestral e resultante anual). Os segmentos oeste (pontos $A$ ao $F$ ) e leste (pontos $G$ ao L) são áreas de influência dos canais de maré, e o segmento central (pontos $F$ ao $G$ ) contém a praia exposta. As setas com sinal positivo indicam o sentido de erosão, transporte e acresção de sedimentos.

\section{Variação acumulada ao longo do ano}

Ao longo do ano de monitoramento, de acordo com as Figuras 3 a 6 , os segmentos de praia exposta tiveram resultante de recuo da LC enquanto os segmentos de canais de maré e estuários tiveram resultante de avanço, nos quatro trechos monitorados. A predominância em recuo da $\mathrm{LC}$ nas praias expostas indicou que o ano monitorado apresentou resultante destrutiva, ou seja, os intervalos destrutivos foram mais efetivos do que os construtivos na dinâmica costeira (Figura 2). Devido ao fato da soma dos avanços da LC nos canais de maré e nos estuários serem maiores do que os recuos da LC nas praias expostas, na maioria dos trechos monitorados (exceto Praia da Soledade) ocorreu resultante de avanço da LC (Figuras 3 a 6) e de acresção no balanço sedimentar volumétrico da LC (Figura 7). Portanto, as resultantes de recuo da LC nas praias expostas e de avanço da LC nos estuários e nos canais de maré mostram a atuação dos agentes dinâmicos costeiros na dinâmica e no transporte sedimentar da resultante anual: as ondas mobilizaram sedimentos nas LC das praias expostas e os colocaram em suspensão, a corrente de deriva litorânea transportou sedimentos no sentido oeste do canal de maré, e as correntes de maré de enchente e os ventos transportaram sedimentos para dentro dos estuários. As setas com sinal positivo das Figuras 3 a 6 indicam o sentido de erosão, transporte e acresção de sedimentos.

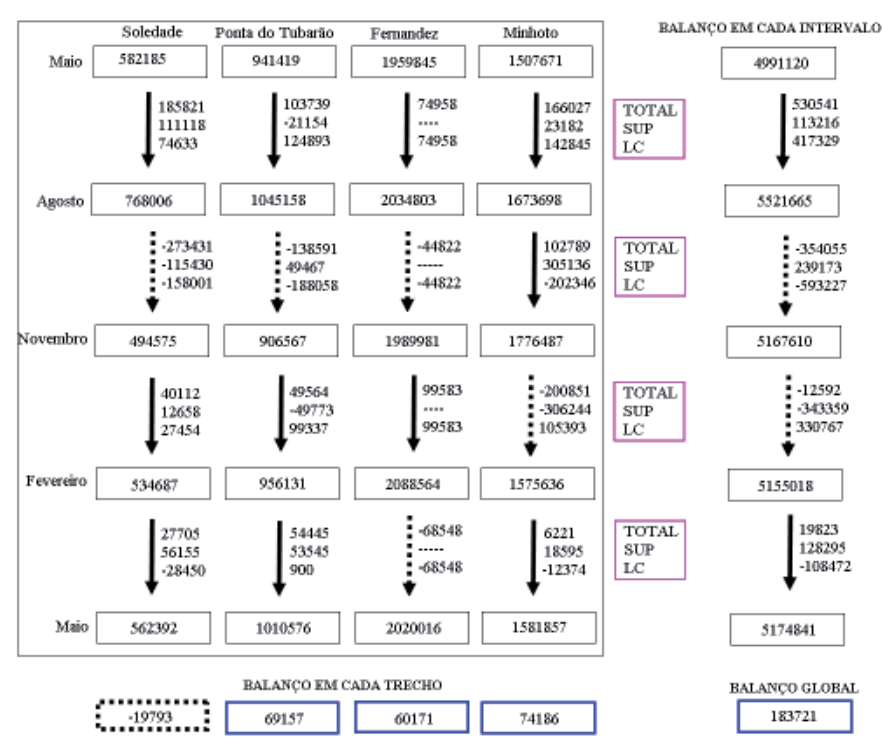

Figura 7-Fluxograma do balanço sedimentar em termos de erosão (seta pontilhada) e acresção (seta contínua) volumétrica para os quatro trechos e nos três intervalos de monitoramento. O balanço em cada intervalo é a soma dos volumes de erosão e acresção dos quatro trechos no intervalo, considerando o sinal da variação. $O$ balanço para cada trecho é a soma dos volumes de erosão $e$ acresção para o trecho nos três intervalos de monitoramento. De cima para baixo, os valores apresentados no lado direito de cada seta vertical representam o volume total (superficie e linha de costa), o volume na superficie da praia ou ilha, e o volume na linha de costa. Unidade: $\mathrm{m}^{3}$.

Na Praia da Soledade (Figura 3), a erosão foi tão intensa na praia exposta do segmento oeste que a linha d'água atingiu a estrada de acesso às instalações dos campos petrolíferos, na 
qual foram implantadas estruturas de contenção de erosão. As maiores acresções ocorreram no canal de maré a oeste e provocou o crescimento da barra arenosa no sentido oeste em 212,0m. Na Ilha Ponta do Tubarão (Figura 4), a erosão na praia exposta gerou o deslocamento da ilha no segmento central (no sentido sul) e no segmento leste (no sentido oeste), de acordo com as setas com sinal positivo na Figura 4. As maiores acresções ocorreram no canal de maré a oeste, responsável pelo crescimento da ilha no sentido sudoeste de 250,0m. Na Ilha do Fernandez (Figura 5), a erosão na praia exposta provocou o deslocamento da ilha no segmento leste (no sentido sudoeste), como mostra as setas com sinal positivo na Figura 5. As maiores acresções ocorreram no canal de maré a oeste, responsável pelo crescimento da ilha no sentido sudoeste em 205,0m. Na Praia do Minhoto, ocorreu intensa acresção no segmento oeste e intensa erosão no segmento leste, sendo que, o segmento central apresentou-se mais estável e com resultante de acresção, indicando ser um segmento de deposição dos sedimentos erodidos e transportados de leste para oeste. A erosão no segmento leste foi tão intensa que a extremidade da praia sofreu deslocamento e rotação no sentido sudoeste.

O balanço sedimentar volumétrico (Figura 7) ao longo do ano teve resultante de acresção devido à ocorrência de volumes de acresção tanto nas LC quanto nas superfícies das praias e ilhas. O maior volume de acresção nas LC em relação ao volume de acresção nas superfícies mostrou a maior influência, no balanço sedimentar, da hidrodinâmica na LC em relação à eólica na superfície ao longo do ano monitorado. Na maioria dos trechos (Ilha Ponta do Tubarão, Ilha do Fernandez e Praia do Minhoto) as maiores variações ocorreram na LC, mostrando a predominância das variações hidrodinâmicas em relação à eólica. Ao longo dos intervalos de monitoramento foi observada a troca de sedimentos entre a LC e as superfícies das praias e ilhas.

\section{Variação no primeiro intervalo de monitoramento (maio/2010 a agosto/2010)}

No primeiro intervalo de monitoramento, de acordo com as Figuras 3 a 6, os segmentos de praia exposta, canal de maré e estuário tiveram resultante de avanço da LC nos quatro trechos monitorados. A predominância em avanço da LC nas praias expostas indicou que o intervalo foi construtivo com a atuação de ondas de baixa energia, ou seja, de acordo com o padrão de dinâmica sedimentar previamente estimado e apresentado na Figura 2. Devido ao avanço ocorrido em todos os segmentos da LC (praia exposta, canal de maré e estuário), ocorreu resultante de avanço da LC (Figuras 3 a 6) e de acresção no balanço sedimentar volumétrico na LC (Figura 7) em todos os trechos monitorados. Portanto, as resultantes de avanço da LC nas praias expostas, nos canais de maré e nos estuários mostram a atuação dos agentes dinâmicos cos- teiros na dinâmica e no transporte sedimentar do intervalo construtivo: as ondas de baixa energia do intervalo depositaram sedimentos nas LC das praias expostas, a corrente de deriva litorânea transportou sedimentos no sentido oeste do canal de maré, e as correntes de maré de enchente e os ventos transportaram sedimentos para dentro dos estuários.

O balanço sedimentar volumétrico (Figura 7) do primeiro intervalo teve resultante de acresção devido à ocorrência de volumes de acresção tanto nas LC quanto nas superfícies das praias e ilhas. O maior volume de acresção nas LC em relação ao volume de acresção nas superfícies mostrou a maior influência, no balanço sedimentar, da hidrodinâmica na LC em relação à eólica na superfície. Em quase todos os trechos (exceto na Praia de Soledade) as maiores variações ocorreram na LC, mostrando a predominância das variações hidrodinâmicas em relação à eólica. Ainda, as resultantes de acresção nas superfícies das praias e ilhas e nas LC indicaram a atuação dos ventos de baixa intensidade do intervalo que, de maneira geral, transportaram parte dos sedimentos depositados na LC (pelas ondas de baixa intensidade) para o interior das superfícies.

\section{Variação no segundo intervalo de monitoramento (agosto/2010 a novembro/2010)}

No segundo intervalo de monitoramento, de acordo com as Figuras 3 a 6, os segmentos de praia exposta e estuário tiveram resultante de recuo da LC enquanto os segmentos de canal de maré tiveram resultante de avanço, nos quatro trechos monitorados. A predominância em recuo da LC nas praias expostas indicou que o intervalo foi destrutivo com a atuação de ondas de alta energia, ou seja, de acordo com o padrão de dinâmica sedimentar previamente estimado e apresentado na Figura 2. Devido ao fato da soma dos recuos da LC nas praias expostas e nos estuários serem maiores do que os avanços da LC nos canais de maré, ocorreu resultante de recuo da LC (Figuras 3 a 6) e de erosão no balanço sedimentar volumétrico na LC (Figura 7) em todos os trechos monitorados. Portanto, as resultantes de recuo da LC nas praias expostas e nos estuários e de avanço da LC nos canais de maré mostram a atuação dos agentes dinâmicos costeiros na dinâmica e no transporte sedimentar do intervalo destrutivo: as ondas de alta energia do intervalo mobilizaram sedimentos nas LC das praias expostas e os colocaram em suspensão, a corrente de deriva litorânea transportou sedimentos no sentido oeste do canal de maré, e as correntes de maré de vazante e os ventos transportaram sedimentos para fora dos estuários.

O balanço sedimentar volumétrico (Figura 7) do segundo intervalo teve resultante de erosão devido ao maior volume de erosão nas LC em relação ao volume de acresção nas superfícies das praias e ilhas, o que mostrou a maior influência, no balanço sedimentar, da hidrodinâmica na LC em relação à eólica na superfície. Nos trechos da Praia da 
Soledade, Ilha Ponta do Tubarão e Ilha do Fernandez as resultantes foram de erosão devido à predominância das variações hidrodinâmicas em erosão na LC. Na Praia do Minhoto, no entanto, a resultante foi de acresção devido às maiores variações em acresção nas superfícies da praia em relação à erosão na LC, o que mostra a predominância eólica do intervalo. Ainda, as resultantes de acresção nas superfícies das praias e ilhas e de erosão nas LC indicaram a atuação dos ventos de alta intensidade do intervalo que, de maneira geral, transportaram parte dos sedimentos erodidos nas LC para o interior das superfícies.

\section{Variação no terceiro intervalo de monitoramento (novembro/2010 a fevereiro/2011)}

No terceiro intervalo de monitoramento, de acordo com as Figuras 3 a 6 , os segmentos de praia exposta tiveram resultante de recuo da LC enquanto os segmentos dos canais de maré e dos estuários tiveram resultante de avanço, nos quatro trechos monitorados. A predominância em recuo da LC nas praias expostas indicou que o intervalo foi destrutivo com a atuação de ondas de alta energia, ou seja, de acordo com o padrão de dinâmica sedimentar previamente estimado e apresentado na Figura 2. Devido ao fato da soma dos avanços da LC nos canais de maré e nos estuários serem maiores do que os recuos da LC nas praias expostas, ocorreu resultante de avanço da LC (Figuras 3 a 6) e de acresção no balanço sedimentar volumétrico da LC (Figura 7) em todos os trechos monitorados. Portanto, as resultantes de recuo da LC nas praias expostas e de avanço da LC nos estuários e nos canais de maré mostram a atuação dos agentes dinâmicos costeiros na dinâmica e no transporte sedimentar do intervalo destrutivo: as ondas de alta energia do intervalo mobilizaram sedimentos nas LC das praias expostas e os colocaram em suspensão, a corrente de deriva litorânea transportou sedimentos no sentido oeste do canal de maré, e as correntes de maré de enchente e os ventos transportaram sedimentos para dentro dos estuários.

O balanço sedimentar volumétrico (Figura 7) do terceiro intervalo teve resultante de erosão devido ao maior volume de erosão nas superfícies das praias e ilhas em relação ao volume de acresção nas LC, o que mostrou a maior influência, no balanço sedimentar, da eólica na superfície em relação à hidrodinâmica na LC. No entanto, nos trechos da Praia da Soledade, Ilha Ponta do Tubarão e Ilha do Fernandez, as resultantes foram de acresção devido à predominância das variações hidrodinâmicas em acresção na LC em relação às variações nas superfícies. Assim, a resultante de erosão do intervalo foi gerada devido à predominância das variações eólicas em erosão nas superfícies da Praia do Minhoto, que foram bem maiores do que as variações nas LC. Portanto, nesse trecho, a grande quantidade de sedimentos erodidos na superfície da Praia do Minhoto influenciou diretamente no balanço sedimentar do intervalo. Ainda, as resultantes de erosão nas superfícies das praias e ilhas e de acresção nas LC indicaram a atuação dos ventos de alta intensidade do intervalo que, de maneira geral, transportaram parte dos sedimentos das superfícies (acumuladas no intervalo anterior) para as LC dos diversos segmentos das LC, sendo aprisionadas nos canais de maré e nos estuários.

\section{Variação no quarto intervalo de monitoramento (fevereiro/2011 a maio /2011)}

No quarto intervalo de monitoramento, de acordo com as Figuras 3 a 6, os segmentos de praia exposta tiveram resultante de recuo da LC enquanto os segmentos de canais de maré e estuários tiveram resultante de avanço, nos quatro trechos monitorados. A predominância em recuo da LC nas praias expostas mostrou que o intervalo não esteve de acordo com o padrão de dinâmica sedimentar previamente estimado e apresentado na Figura 2, que seria de intervalo construtivo. Assim, o ciclo medido diferiu do ciclo estimado no quarto intervalo, o que resultou no aumento do período erosivo ao longo do ano. Devido ao fato da soma dos recuos da LC nas praias expostas serem maiores do que os avanços da LC nos canais de maré e nos estuários, na maioria dos trechos monitorados (exceto na Ilha Ponta do Tubarão) ocorreu resultante de recuo da LC (Figuras 3 a 6) e de erosão no balanço sedimentar volumétrico da LC (Figura 7). Portanto, as resultantes de recuo da LC nas praias expostas e de avanço da LC nos canais de maré e nos estuários mostram a atuação dos agentes dinâmicos costeiros na dinâmica e no transporte sedimentar do intervalo: as ondas invadiram as praias expostas e continuou o processo de recuo da LC dos intervalos anteriores, a corrente de deriva litorânea transportou sedimentos no sentido oeste do canal de maré, e as correntes de maré de enchente e os ventos transportam sedimentos para dentro dos estuários. No entanto, a resultante de erosão do intervalo e os mecanismos de transporte de sedimentos das praias expostas para os canais de maré e os estuários ocorreram com a atuação de ondas e ventos de baixa intensidade do período construtivo, ou seja, de maneira diferente ao processo de erosão ocorrido nos intervalos anteriores.

O balanço sedimentar volumétrico (Figura 7) do quarto intervalo teve resultante de acresção devido ao maior volume de acresção nas superfícies das praias e ilhas em relação ao volume de erosão nas LC, o que mostrou a maior influência, no balanço sedimentar, da eólica na superfície em relação à hidrodinâmica na LC. No entanto, observa-se que o intervalo foi marcado pelas menores variações sedimentares ocorridas ao longo do ano, tanto hidrodinâmica na LC quanto eólica nas superfícies, o que comprovou que o intervalo foi realmente o de menor intensidade e atuação dos agentes dinâmicos costeiros, com ondas de baixa energia típicas de intervalo construtivo. 


\section{Análises das causas da erosão sedimentar nas praias expostas}

O recuo da LC das praias expostas mensurado no segundo e no terceiro intervalos de monitoramento mudou a paisagem costeira das praias e ilhas monitoradas. Como esses intervalos foram característicos de ondas com alta energia, elas avançaram em direção ao continente, erodiram as praias expostas e atingiram feições morfológicas que antes eram da pós-praia, como bermas e dunas frontais, gerando um cenário de intensa erosão costeira. Feições morfológicas típicas de praias em erosão foram encontradas, como escarpas em bermas e dunas frontais, paleomangues e manguezais ativos expostos na zona de estirâncio. Em uma praia estável, o ciclo anual de construção e destruição das praias, caracterizado pelo avanço e recuo da LC, deveria ser um processo natural ocorrido na faixa de praia devido à ação combinada dos agentes dinâmicos costeiros. No entanto, a intensa erosão costeira ocorrida na pós-praia nos meses de maior intensidade nos agentes dinâmicos evidenciou a instabilidade das praias expostas, que pode estar associada a várias causas atuando em conjunto.

A principal causa dessa instabilidade é o maior período destrutivo das praias (agosto a fevereiro) em relação ao construtivo (março a julho), ou seja, um maior período de erosão em relação ao de acresção ao longo do ano. A contínua remoção de sedimentos se inicia em agosto (início do período destrutivo), quando as praias estão com estoque sedimentar máximo devido ao período anterior construtivo, e termina em fevereiro (fim do período destrutivo), quando elas estão com estoque sedimentar mínimo. Assim, os meses de verão são críticos para o avanço da LC e a consequente erosão costeira, pois, é nesse período que as praias estão mais planas e com menor estoque sedimentar, devido ao longo período destrutivo, e as ondas possuem maior energia, ou seja, maior potencial de deslocamento horizontal da linha d'água. O período destrutivo maior do que o construtivo evidencia uma tendência à maior remoção de sedimentos do que de acresção ao longo do ano, ou seja, a planificação das praias com o consequente avanço da LC.

No ciclo monitorado, entre maio de 2010 a maio de 2011, a erosão foi tão intensa que ocorreu a continuidade do processo de recuo da LC no quarto intervalo (fevereiro a maio de 2011), tipicamente construtivo e quando o sistema praial deveria iniciar o processo de alimentação natural das praias. Isso mostra que o sistema praial não teve estoque sedimentar suficiente para alimentar as praias durante esse intervalo construtivo ao ponto de possibilitar que a praia retornasse, no fim do intervalo (maio de 2011), à situação original do início do ciclo monitorado (maio de 2010). Assim, mesmo o intervalo sendo construtivo com a atuação das ondas e ventos de baixa intensidade, o processo de recuo da LC continuou durante o intervalo. No entanto, o recuo da LC ocorreu de maneira diferente aos intervalos anteriores, quando as ondas de alta energia erodiam a praia exposta. Nesse caso, o recuo da LC ocorreu pelo processo de inundação, no qual as ondas de baixa intensidade invadiram a praia devido às mesmas estarem mais planas e com cotas topográficas mais baixas (devido à erosão ocorrida no longo período destrutivo anterior e da falta de estoque sedimentar para alimentar as praias). Observa-se que, em termos de inundação por invasão da LC, o rebaixamento das superfícies das praias tem efeito semelhante à da elevação do nível do mar.

Esse déficit no suprimento sedimentar das praias pode estar relacionado à intensa seca ocorrida no ano de 2010. Pela análise dos dados climatológicos disponibilizados pelo INMET (Figura 8) observa-se que no ano de 2010 ocorreram chuvas consideráveis apenas no mês de abril, quando na normal climatológica de 1961 a 1990 e nos anos antecessores a 2010 as chuvas ocorreram de janeiro a agosto (com mais altas intensidades entre fevereiro e maio), o que mostra que o ano monitorado foi o de mais intensa seca dos últimos anos. Portanto, a escassez de chuvas no período tipicamente construtivo e chuvoso provocou a redução da quantidade de sedimentos fluviais transportados para as praias, tornando-as com menor estoque sedimentar do que nos anos anteriores. Assim, em agosto de 2010, início do intervalo destrutivo (e fim do construtivo) as praias com estoque sedimentar reduzido em relação aos anos anteriores foram mais susceptíveis ao avanço da LC e à erosão costeira provocada pelas ondas de alta energia. Em fevereiro de 2011, no final do período destrutivo (e início do construtivo), quando as ondas de baixa energia deveriam iniciar o processo de acresção das praias, o estoque sedimentar reduzido não permitiu que elas retornassem à situação original do ciclo anterior, em maio de 2011. Além da redução do estoque sedimentar, a falta de chuvas aumenta a temperatura das praias e provoca a secagem dos sedimentos, o que potencializa o transporte eólico, ou seja, acelera o processo de erosão eólica das praias.

Com o objetivo de entender a ocorrência da intensa seca na área de estudo, foi observada a correlação entre as chuvas acumuladas para os anos de 2010 (ano monitorado), 2009 e 2008 (anos anteriores ao monitoramento), apresentadas na Figura 8, e as anomalias de Temperatura da Superfície do Mar (TSM) no Oceano Pacífico Central. Tais anomalias são responsáveis pelo surgimento dos fenômenos climáticos denominados de El Niño e La Niña: quando anomalias negativas da TSM, denominadas de $L a$ Niña, são observadas nessa porção do Oceano Pacífico, ocorre um aumento da precipitação e da vazão dos rios na região Nordeste do Brasil; ao contrário, as anomalias 
positivas da TSM, denominadas de El Niño, provocam escassez de chuvas na região Nordeste do Brasil. Nas análises, foi constatado que nos anos de 2008 e 2009 ocorreram anomalias negativas da TSM, ou seja, a grande quantidade de chuva acumulada acima da normal climatológica nesses anos pode ser correlacionada com o fenômeno La Niña. Por outro lado, no ano de 2010 ocorreu anomalia positiva da TSM, ou seja, a escassez de chuva acumulada abaixo da normal climatológica nesse ano pode ser correlacionada com o fenômeno El Niño.

Outro fator que pode contribuir na instabilidade das praias expostas é o intenso transporte de sedimentos gerado pelas correntes de deriva litorânea (que têm sentido oeste), evidenciadas pelo crescimento das extremidades oeste dos trechos monitorados e pela migração dos canais de maré. Nos intervalos de intensa ação dos agentes dinâmicos costeiros, quando o impacto das ondas sobre a LC remove sedimentos e os coloca em suspensão, a corrente de deriva litorânea dificulta o transporte de sedimentos pelas correntes de maré de vazante em direção ao mar, em forma de bancos arenosos submersos. Assim, parte dos sedimentos que seriam armazenados nos bancos arenosos, e que retornariam à LC no período construtivo, é então transportado ao longo da praia no sentido da corrente de deriva litorânea. O problema se agrava devido ao fato da corrente de deriva litorânea estar presente em toda a praia exposta, o que faz com que toda ela sofra com o deslocamento de sedimentos para fora da área (à oeste), com trechos consideráveis de acresção somente nos canais de maré e, em certos períodos, nos estuários.

As hipóteses levantadas anteriormente sobre as causas da intensa dinâmica costeira se apoiaram na dinâmica natural do sistema em períodos de curta duração, baseada na atuação dos agentes dinâmicos costeiros, nos processos climáticos ou nas correntes litorâneas. No entanto, Nascimento (2009) destaca como fator adicional ao aumento da erosão em trechos específicos das praias e ilhas barreiras, a baixa resiliência do ambiente diante do aumento na implantação de atividades industriais em áreas onde se localizam células sedimentares relevantes ao equilíbrio sedimentológico da região. Como exemplo, destacou a instalação de tanques de salinas em áreas úmidas e de planície de deflação na Praia da Soledade; os tanques evaporadores foram construídos sobre uma zona de aporte de sedimentos eólicos para a LC em frente ao Campo de Petrolífero de Macau e as dunas móveis; outro fato foi instalação de acessos para as bases dos poços de petróleo em trechos onde ocorria acúmulo de células sedimentares. A ocupação de tais trechos praiais impediu a ação completa e efetiva dos processos costeiros sobre os sedimentos, afetando o sistema de defesa natural da zona costeira contra a erosão, disponível nos sistema duna-praia, acarretando localmente na intensificação da ação erosiva e alterando a dinâmica natural dos ciclos ambientais.

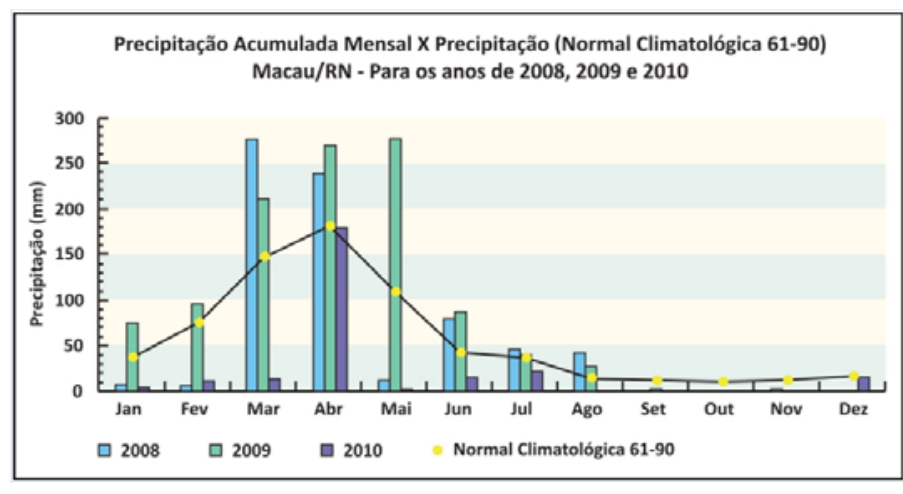

Figura 8 - Precipitação acumulada mensal para os anos de 2008, 2009 e 2010 vs. Precipitação (Normal Climatológica 1961-1990) a partir de dados da Estação Meteorológica de Macau-RN. Fonte: Instituto Nacional de Meteorologia (INMET).

\section{Conclusões}

Este trabalho monitorou a evolução morfológica em escala intra-anual (sazonal), com levantamentos trimestrais, de áreas costeiras e estuarinas de trecho do litoral arenoso no RN, setor sensível ambientalmente e de intensa dinâmica costeira (erosão/acresção sedimentar) onde ocorrem atividades industriais, tais como a salineira, a petrolífera, a eólica e a de carcinicultura, localizadas na faixa de orla. Para isso, foram geradas LC e MDE a partir de métodos geodésicos de precisão, em épocas correspondentes ao início, meio e fim dos períodos construtivos e destrutivos das praias expostas. Os parâmetros avaliados entre os levantamentos permitiram analisar as correlações entre as variações medidas nos diversos segmentos das LC (praia exposta, estuários e canais de maré) e a atuação dos agentes dinâmicos costeiros atuantes (clima, ventos, ondas e correntes) nos intervalos dos monitoramentos.

Os agentes dinâmicos costeiros tiveram papéis importantes na dinâmica sedimentar sazonal da área de estudo nos diversos segmentos de LC. As ondas de mar aberto (vindas de NE) tiveram o papel de construção e destruição das praias expostas, com acresção no primeiro intervalo e erosão nos demais. A corrente de deriva litorânea (sentido oeste) deslocou os sedimentos erodidos da praia exposta (no sentido oeste) e os depositou nos canais de maré. As correntes de maré e os ventos transportaram sedimentos para o interior dos estuários (exceto no segundo intervalo), que, favorecidos pelo fluxo hidrodinâmico de calmaria, foram depositados em suas margens. Na maioria dos trechos, a influência hidrodinâmica na LC foi maior do que a eólica na superfície, o que mostrou a grande intensidade dos processos costeiros ocorridos nas LC. Ao longo dos intervalos de monitoramento foi possível verificar a troca de sedimentos entre as superfícies de praias (e ilhas barreiras) e as LC, devido à atuação eólica e da hidrodinâmica no transporte e na disponibilização dos sedimentos. 
O recuo da LC ocorrido no segundo e no terceiro intervalos de monitoramento (agosto a novembro e novembro a fevereiro) mudou a paisagem costeira das praias expostas e gerou um cenário de intensa erosão costeira. A principal causa foi o maior período destrutivo das praias (agosto a fevereiro) em relação ao construtivo (março a julho), ou seja, um maior período de erosão em relação ao de acresção ao longo do ano, o que evidenciou uma tendência à planificação das praias e ao rebaixamento das cotas topográficas. Assim, os meses de verão (final do período destrutivo) foram identificados como os mais críticos para a erosão costeira, pois nesse período as praias estavam mais planas e as ondas de mais alta intensidade, ou seja, mais susceptíveis ao avanço da linha d'água. A continuidade do processo de erosão no quarto intervalo, quando as praias deveriam iniciar o processo de acresção, evidencia a intensa erosão dos intervalos anteriores (que deixaram as praias mais planas) e a insuficiência de suprimento sedimentar no início do período construtivo (fevereiro de 2011) para possibilitar a recuperação das praias. Essa insuficiência de suprimento sedimentar nas praias foi correlacionada com a seca severa ocorrida no ano de 2010, no qual somente o mês de abril apresentou chuvas consideráveis, o que provocou redução da quantidade de sedimentos fluviais transportados para as praias. A escassez de chuvas ocorrida no ano de 2010 foi então correlacionada aos efeitos provocados na região pelo fenômeno climático El Niño.

A intensa erosão costeira mensurada no segundo e terceiro intervalos de monitoramento (agosto a novembro e novembro a fevereiro) e a incapacidade das praias expostas em se recuperar no quarto intervalo (fevereiro a maio) mostraram que as praias e ilhas barreiras monitoradas apresentaram-se como sistemas de alta instabilidade, dinâmicas e sensíveis, sofrendo mudanças significativas na LC e na geomorfologia, além das trocas de sedimentos com regiões adjacentes. Essa intensa erosão costeira é preocupante para a manutenção das praias e ilhas barreiras da área de estudo, que tendem a desaparecer em poucas décadas de acordo com prognósticos realizados recentemente. No entanto, esforços estão sendo feitos com o objetivo de conhecer com maior detalhe a dinâmica sedimentar (erosão/acresção) e as características evolutivas da área de estudo, no passado, no presente e com visão futura, nas diversas escalas espaciais e temporais, para subsidiar alternativas eficazes e viáveis para evitar e/ou reduzir os impactos da dinâmica sedimentar sobre os ecossistemas costeiros e as atividades industriais, sobretudo aquelas que oferecem alto risco de contaminação local, como a indústria petrolífera instalada no prisma praial emerso, de alta instabilidade sedimentar.

\section{Agradecimentos}

Esta pesquisa foi financiada com recursos de Projetos Cooperativos de Pesquisa Norte-Nordeste da REDE 05PETROMAR (CTPETRO-FINEP/PETROBRAS/CNPq): Subprojetos MOLECO e CRONALOG. As atividades foram desenvolvidas com o apoio logístico do Laboratório de Geoprocessamento do Departamento de Geologia da UFRN (GEOPRO/DG/UFRN). Os autores agradecem especialmente à CAPES pela concessão de Bolsa de Doutorado ao primeiro autor.

\section{Referências bibliográficas}

AMARO, V. E.; SANTOS, M.S.T; SOUTO, M. V. S. Geotecnologias aplicadas ao monitoramento costeiro: Sensoriamento Remoto e Geodésia de precisão (ISBN: 9888591374601). Natal: Editora Natal, 2012.

BAPTISTA, P.; BASTOS, L.; BERNARDES, C.; CUNHA, T.; DIAS, J.A. Monitoring Sandy Shores Morphologies by DGPS - A Practical Tool to Generate Digital Elevation Models. Journal of Coastal Research, Coconut Creet, v. 24, n. 6, p. 1516-1528, 2008.

BOAK, E.H.; TURNER, I.L. Shoreline Definition and Detection: A Review. Journal of Coastal Research, Coconut Creet, v. 1, n. 4, p. 688-703, 2005.

CALLIARI, L.J.; MUEHE, D.; HOEFEL, F.G.; TOLDO JR, E. Morfodinâmica Praial: uma breve revisão. Revista Brasileira de Oceanografia, São Paulo, v. 51, p. 63 - 78, 2003.

CHAVES, M.S.; VITAL, H.; SILVEIRA, I.M.; SANTOS, D.A.S.. Beach Morphodynamics of the Serra Oil Field (NE, Brazil). Journal of Coastal Research, Coconut Creet, v. 39, p. 594-597, 2006.

COWART, L; WALSH, J.P; CORBETT, D.R. Analyzing Estuarine Shoreline Change: A Case Study of Cedar Island, North Carolina. Journal of Coastal Research, Coconut Creet, v. 26, n. 5, p.817-830, 2010.

ESTEVES, L.S.; WILliAMS, J.J.; DILLENBURG, S.R. Seasonal and Interanual Influences on the Patterns of Shoreline Changes in Rio Grande do Sul, Southern Brazil. Journal of Coastal Research, Coconut Creet, v. 22, n. 5, p.1076-1093, 2006.

FEATHERSTONE, W.E.; DENTITH, M.C.; KIRBY, J.F. Strategies for the accurated determination of orthometric heights from GPS. Survey Review, Bristol, v. 34, p. 278-295, 1998.

GUERRA, A.J.T.; JORGE, M.C.A. Processos erosivos e recuperação de áreas degradadas. São Paulo: Editora Oficina de Textos, 2013.

GRIGIO, A.M.; SOUTO, M.V.S.; CASTRO, A.F.; AMARO, V.E.; VITAL, H.; DIODATO, M.A. Method of analysis of the coastline evolution based in remote sensing and geographical 
information system products: Guamaré District Rio Grande do Norte - Northeast of Brazil. Journal of Coastal Research, Coconut Creet, v. 42, n. 2, p.412- 421, 2005.

KLEMAS, V. Remote Sensing Techniques for Studying Coastal Ecosystems: An Overview. Journal of Coastal Research, Coconut Creet, v. 27, n. 2, p. 2-17, 2011.

IBGE (FUNDAÇÃO INSTITUTO BRASILEIRO DE GEOGRAFIA E ESTATÍSTICA). Informações obtidas da página do IBGE na internet. IBGE. Disponível em: < http:// www.ibge.gov.br>Acesso em: 01 janeiro 2011.

MONICO, J.F.G. Posicionamento pelo GNSS: descrição, fundamentos e aplicações. São Paulo: Editora Unesp, 2007.

MOORE, L.J.; RUGGIERO, P.; LIST, J.H. Comparing Mean High Water and High Water Line shorelines: Proxy Datum Offsets be Incorporate into shoreline Change Analyses. Journal of Coastal Research, Coconut Creet, v.22, p. 894-905, 2006.

NASCIMENTO, M.C. A erosão costeira e sua influência sobre a atividade petrolífera: alternativas sustentáveis na mitigação de impactos ambientais. 2009. 229 f. Dissertação (Mestrado em Geodinâmica e Geofísica) - Departamento de Geologia, Universidade Federal do Rio Grande do Norte, Natal, 2009.

ROCHA, C.P.; ARAÚJO, T.C.M.; MENDONÇA, F.J.B. Methodology for Location of Shorelines using 3D-GPS Positioning: A Case Study at Sauaçui Beach, Northeast Brazil. Journal of Coastal Research. Coconut Creet, v.25, n.4, p.10521058, 2009.
SANTOS, M.S.T.; AMARO, V.E. Rede geodésica para o monitoramento costeiro do Litoral Setentrional do Estado do Rio Grande do Norte. Boletim de Ciências Geodésicas, Curitiba, v. 17, n. 4, p.571-585, 2011a.

SANTOS, M.S.T.; AMARO, V.E.; SOUTO, M.V.S. Metodologia geodésica para levantamento de linha de costa e modelagem digital de elevação de praias arenosas em estudos de precisão de geomorfologia e dinâmica costeira. Revista Brasileira de Cartografia, Rio de Janeiro, v. 63, n. 63/5, p. 663-681, 2011 b.

SANTOS, M.S.T.; SÁ, N.C de. O uso do GPS em levantamentos geofísicos terrestres. Revista Brasileira de geofísica, Rio de Janeiro, v. 24, n. 1, p. 63-80, 2006.

SEEBER, G. Satellite Geodesy: Fundations, methods and applications. N. York: Walter de Gruyter, 1993.

SOUTO, M.V.S. Análise da evolução costeira do Litoral Setentrional do Estado do Rio Grande do Norte, região sob influência da indústria petrolífera. 2009. 177 f. Tese (Doutorado em Geodinâmica e Geofísica) -Departamento de Geologia, Universidade Federal do Rio Grande do Norte, Natal, 2009.

WRIGHT, L.D.; SHORT, A.D. Morphodynamic variability of beaches and surfzones: A synthesis. Marine Geology, Amsterdam, v. 56, p. 92-118, 1984. 